\title{
Medical Ethics in Bangladesh
}

\section{R E Mahbub ${ }^{1}$}

Ethical Medical Practice is available in this part of the world since time of Shasruta and Charaka Sanhita. Hippocratic oath was formulated much later in Greek.

Physicians are often viewed as a demi God and their decisions are taken as gosple truth without any doubt or misgiving. This imposes immense responsibilities on physician to maintain ethically correct and honest approach in their dealing with ther patients.

World Medical Association at its third general assembly in Geneva, September 1948 proposed certain codes of ethics in the form of an oath to be taken by all members of the medical profession at the time of entering into the profession. A year later the association adopted this code of ethics which is popularly known as the international code of medical ethics.

Bangladesh Medical and Dental Council is the body to regulate the conduct of the Medical Professionals of Bangladesh. After graduation they have to register themselves with the council. They have to agree to abide by the codes of declaration.

"I pledge to consecrate my life to the service of humanity. I will not use my knowledge contrary to the laws of humanity. I will maintain the utmost respect of human life from the time of conception". It also includes responsibilities of the physician, professional service, duties of the physician to their patients, and to each other, to the public and the profession at large.

In other way this code of ethics is divided into different sections. Each sector deals with different issues namely

* Duties of Physician to their patients.

* Duties of Physician to their profession.

* Duties of Physician to another physician.

Duties of Physician to patient consultation.

The sector regulates ethical considerations about

* The guidance to doctors on their behavior and responsibilities.

* The extent and limitation about advertisement and terms of payment for professional services.

* The issues of commission or gifts.

* Procuring of patients.

In addition Medical Council looks into the public interest for registration of doctor's qualification. The council maintains disciplinary control over medical practitioners with regard to misconduct, negligence as well as behavior in their medical practice.

\author{
1. Dr. Rashid-E-Mahbub \\ Ex. President \\ Bangladesh Medical Association
}

They form committees, and take actions for any violation of ethical code or malpractice; the maximum punishment the council can provide is cancellation of his or her registration for short time or permanently.

Medical ethics in research is dealt by a separate organization, Bangladesh Medical Research Council which regulates research concerned with clinical, epidemiological and sociological aspects of health and disease. It also includes drug trial. In executing law of the land one needs permission from appropriate authority for clinical evaluation of the new drug. These all are needed as ethical guidelines for the safety of public life. It includes guidelines for informed consent, guidelines for confidentiality and others. An ethical review committee or ethical committee of the institution looks into reserch bioethics. Bangladesh is lacking in appropriate laws and codes regarding rescarch ethics.

At present Bangladesh is going through a social transformation, economic growth and increasing disparity, widening of gap between poor and rich, increasing literacy, empowerment of women, increased health awareness, increasing life expectancy, decreasing infant mortality and maternal mortality. There is a change of life style of the people and family dynamics, health seeking behavior, improvement of information technology and rapid urbanization. These are the challenges in the health service.

In Bangladesh, medical services are provided by public and private sectors. In public sector there are scarcities of amenities and beds. It is overcrowded and the physicians have to face the ethical dilemma in their choice of treatment and priority. In private sector it is costly and beyond the reach of poor people. There is a lack of good monitoring and proper laws. In addition, advancements in transplantation and assisted reproduction necessitate new regulatons of medical ethics.

In teaching Medical Ethics colonial legacy is being followed. It is taught in the department of Forensic Medicine emphasizing negligence and malpractice; but medical students mostly follow the professional conduct of their seniors rather than learning through text books and class instructions

It is the time for restructuring the guidelines of medical ethics and incorporate them in the undergraduate medical curriculum, strengthening the Medical Council, sensitizing the physicians and upgrading the relevant laws.

\section{References:}

1. Bangladesh Medical Council Act 1973.

2. Bangladesh Medical Dental Council Act 1960.

3. Research Information and Communication on Health Bangladesh Medical Research Council.

4. Health Ethics in South Asis WHO publication 1999

5. World Medical Association Proceeding. 